\title{
Phenology of some chironomid species (Diptera, Chironomidae) of the Middle Urals
}

\author{
Andrey B. Krasheninnikov'
}

Krasheninnikov AB. 2012. Phenology of some chironomid species (Diptera, Chironomidae) of the Middle Urals. Fauna norvegica 31: 55-63.

Flight period results of chironomid species from the Middle Urals are grouped into eight categories. Six different peaks of chironomid flight activity during the year are established, namely: early-spring, late-spring, July, late-summer, early-autumn and winter. The flight periods of chironomids from the Middle Urals and southern Swedish lakes are compared.

doi: 10.5324/fn.v31i0.1371. Received: 2011-11-02. Accepted: 2012-06-22.

Published on paper and online: 2012-10-17.

Keywords: Chironomidae, phenology, Middle Urals, Russia

1. Perm' State University, Bukireva str., 15 Perm 614990 Russia

E-mail: krasheninnikov2005@yandex.ru

\section{INTRODUCTION}

Dynamics of seasonal activity of the imago is an important aspect of insect ecology. Differences in the development cycles of chironomids are observed depending on climatic conditions, geographical location and latitude (Brundin 1949). These differences enable the adults of various non-biting midge species to modify their emergence depending on cyclically varying environmental conditions which occur throughout different periods of the year (or from year to year), such as favorable or adverse weather, fluctuations in food resources for the larvae, etc. Studying the phenology is important for understanding the ecological adaptations of different species to climatic conditions in a region and it enables predictions to be concerning the status of insect's populations. In Russia, detailed data on chironomid phenology is included in the works of Shilova (1976) for the Rybinsk Reservoir and of Yavorskaya (2010) for the Lower Amur River basin.

Data on chironomid phenology is very incomplete because the non-biting midge fauna of the Urals is very poorly studied. Tauson (1947), Gromov (1951, 1953), Aleksevnina (1988), Pankov (2004) and Pozdeev (2010) have conducted investigations of the chironomid fauna in this region have, but most of these studies concentrated their attention only on the immature stages.

The main purpose of this work was to investigate chironomid phenology of the subfamilies Diamesinae, Prodiamesinae and Orthocladiinae in the Middle Urals.

\section{MATERIAL AND METHODS}

The material for this investigation was collected from 2004 to 2011 at 28 sites in the Middle Urals (including lotic and lentic waters). Two sites were studied regularly, the first was located on the Sylva River (between the village of Torgovishche and the town of Suksun) and the second was located at the outflow of the hydrosulphuric spring by the Irgina River near the town of Klyuchi. At these two sites adult male chironomids were collected every 7-10 days from 2009 to 2010 mainly with sweep nets. The material was preserved in Oudemans' solution and later mounted on slides in Berlese's fluid or Euparal.

Publications of Makarchenko (1985, 1998, 2006), Makarchenko and Makarchenko (2005, 2006a, b, 2009a, b, 2010a, b, c), Brundin (1947, 1949, 1956, 1966), Cranston and Sæther (1982), Cranston et al. (1989), Fu et al. (2009, 2010a, 2010b), Hirvenoja (1973); Hirvenoja and Hirvenoja (1988), Langton and Pinder (2007), Lehmann (1969, 1972), Oliver and Roussel (1983), Rossaro and Lencioni (2000), Sæther (1969, 1975, 1976, 1977, 1985a, 1985b, 1989, 1990, 1995, 2004), Sæther and Wang (1995) Sæther et al. (1984), Schlee (1968), Strenzke (1950, 1960), Tuiskunen $(1985,1986)$, Tuiskunen and Lindeberg (1986) and Willassen et al. (2005) were used for identification. The Sylva River site is hyporhitral and the water chemistry (averaged for 2003) is as follows: $\mathrm{pH} 8.06$; total dissolved solids $0.387 \mathrm{~g} / 1 ; \mathrm{O}_{2} 10.54 \mathrm{mg} / 1 ; \mathrm{N}_{\mathrm{NH}_{4}+}+0.25 \mathrm{mg} / 1 ; \mathrm{NO}_{2}{ }^{-} 0.03 \mathrm{mg} / \mathrm{l} ; \mathrm{NO}_{3}{ }^{-}$ $2.24 \mathrm{mg} / \mathrm{l} ; \mathrm{PO}_{4}^{3-} 0.06 \mathrm{mg} / \mathrm{l} ; \mathrm{SO}_{4}^{2-} 73.91 \mathrm{mg} / \mathrm{l} ; \mathrm{Cl} 4.91 \mathrm{mg} / \mathrm{l}$. 
The Irgina River site is metarhitral and the water chemistry (for July 2005) is as follows: $\mathrm{pH} 8.81 ; \mathrm{O}_{2} 11.03 \mathrm{mg} / \mathrm{l}$; total dissolved solids $0.142 \mathrm{~g} / \mathrm{l} ; \mathrm{SO}_{4}^{2-} 48.97 \mathrm{mg} / \mathrm{l} ; \mathrm{PO}_{4}^{3-} 0.054 \mathrm{mg} / \mathrm{l}$; $\mathrm{N}_{\mathrm{NH}_{4}}{ }^{+} 168.0 \mathrm{mg} / \mathrm{l} ; \mathrm{NO}_{2}^{-} 0.02 \mathrm{mg} / \mathrm{l}$. Water chemistry of the hydrosulphuric spring (for July 2005) is as follows: $\mathrm{pH} 7.82 ; \mathrm{O}_{2}$ $11.19 \mathrm{mg} / \mathrm{l} ; \mathrm{H}_{2} \mathrm{~S}$ and $\mathrm{S}^{2-} 0.1 \mathrm{mg} / \mathrm{l}$; total dissolved solids $0.387 \mathrm{~g} / \mathrm{l}$; $\mathrm{SO}_{4}{ }^{2-} 75.60 \mathrm{mg} / \mathrm{l} ; \mathrm{PO}_{4}^{3-} 0.1 \mathrm{mg} / \mathrm{l} ; \mathrm{N}_{\mathrm{NH}_{4}}{ }^{3} 307.2 \mathrm{mg} / \mathrm{l} ; \mathrm{NO}_{2}^{-} 0.01$ $\mathrm{mg} / \mathrm{l}$. One of the interesting features of the microorganisms in the spring is the large number of colorless filamentous sulfuroxidizing bacteria Thiothrix sp. and photoautotrophic purple bacteria Chromatium sp.

\section{RESULTS}

The results of these studies revealed differences in flight periods for different species: 13 species fly only in spring, 19 species fly from spring to summer, 15 species fly from spring to autumn, 34 species fly only in summer, six species fly from summer to autumn, four species fly in spring and in autumn, three species fly only in autumn and one species flies from autumn to spring including winter.

Fly only in summer: Acamptocladius reissi Cranston et Sæther, 1981; Allocladius nanseni (Kieffer, 1926); Bryophaenocladius akiensis (Sasa, Shimomura et Matsuo, 1991); B. inconstans (Brundin, 1947); Corynoneura aurora Makarchenko et Makarchenko, 2010; C. lacustris Edwards, 1924; Cricotopus (s. str.) albiforceps (Kieffer, 1916); C. (s. str.) bicinctus (Meigen, 1818); C. (s. str.) festivellus (Kieffer, 1906); C. (s. str.) cf. politus
(Coquillett, 1902); C. (s. str.) similis Goetghebuer, 1921; C. (s. str.) triannulatus (Macquart, 1826); C. (s. str.) vierriensis Goetghebuer, 1935; C. (Isocladius) laetus Hirvenoja, 1973; C. (I.) obnixus (Walker, 1856); Doncricotopus dentatus Tuiskunen, 1985; Limnophyes angelicae Sæther, 1990; L. edwardsi Sæther, 1990; Metriocnemus (s. str.) atriclava Kieffer, 1921; M. (s. str.) caudigus Sæther, 1995; Nanocladius (s. str.) balticus (Palmén, 1959); N. (s. str.) distinctus (Malloch, 1915); Odontomesa fulva (Kieffer, 1919); Parakiefferiella smolandica (Brundin, 1947); Paratrichocladius goetghebueri Spies, 2011; Pseudosmittia danconai (Marcuzzi, 1947); Pseudosmittia mathildae Albu, 1968; Potthastia longimanus Kieffer, 1922; Rheocricotopus (Psilocricotopus) atripes (Kieffer, 1913); Rh. (P.) chalybeatus (Edwards, 1929); Smittia controversa Makarchenko et Makarchenko, 2005; S. nudipennis (Goetghebuer, 1913); S. pratorum (Goetghebuer, 1927); Thienemanniella oyabedilata Sasa, Kawai et Ueno, 1988.

Fly from spring to summer: Acricotopus lucens (Zetterstedt, 1850); Bryophaenocladius ictericus (Meigen, 1830); B. subparallelus (Malloch, 1915); Corynoneura arctica Kieffer, 1923; C. carriana Edwards, 1924; C. gratias Schlee, 1968; C. scutellata Winnertz, 1846; Cricotopus (Isocladius) cf. intersectus (Stæger, 1839); Limnophyes asquamatus Søgaard Andersen, 1937; L. minimus (Meigen, 1818); Metriocnemus (s. str.) eurynotus (Holmgren, 1883); M. (s. str.) picipes (Meigen, 1818); Nanocladius (s. str.) cf. minimus Sæther, 1977; Paracladius conversus (Walker, 1856); Paratrichocladius rufiventris (Meigen, 1830); Prodiamesa olivacea (Meigen, 1818); Pseudodiamesa nivosa (Goetghebuer, 1928); Rheocricotopus

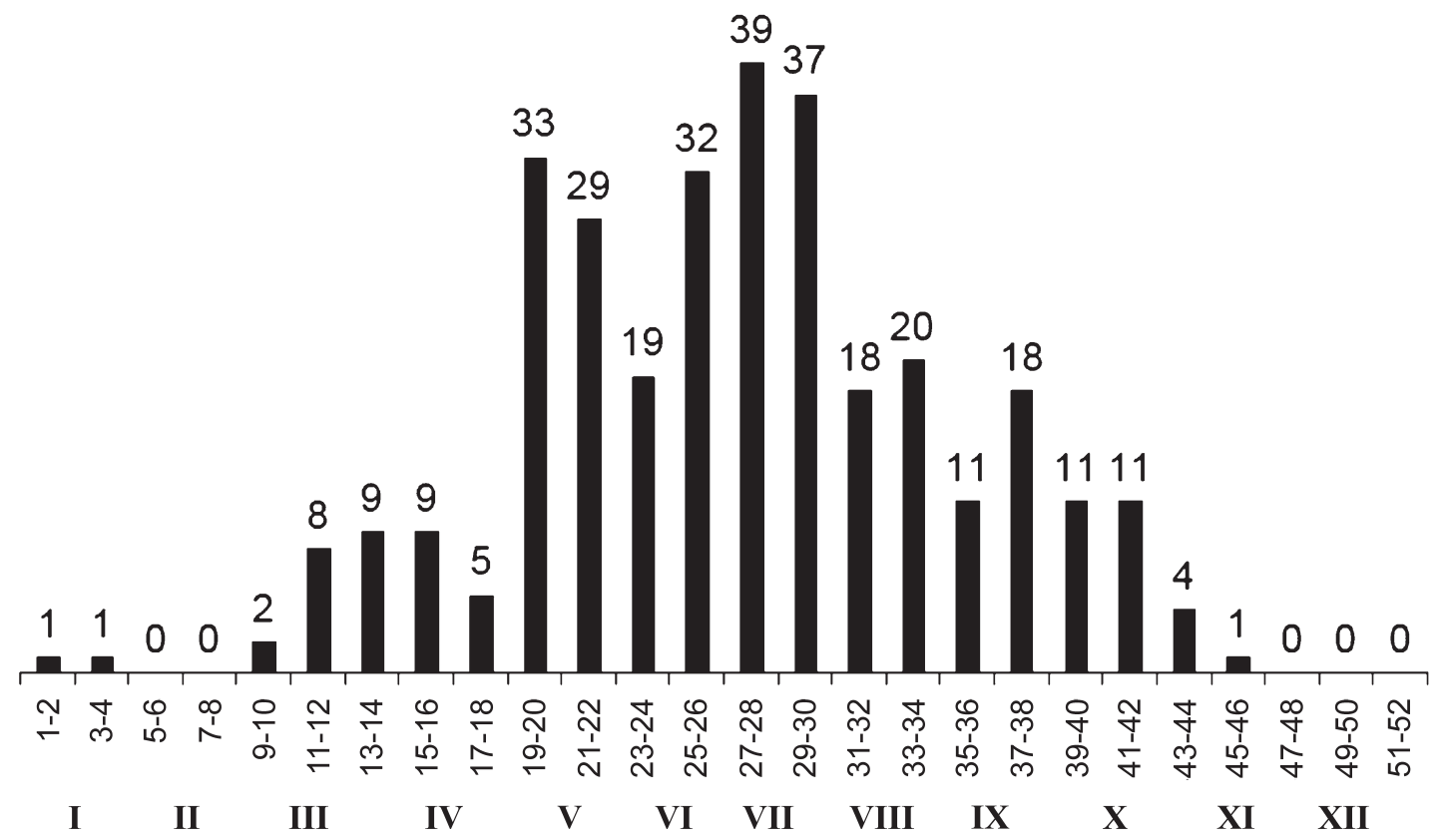

Figure I. Dynamics of chironomid species diversity in the Middle Urals through the year. Numbers of weeks (Arabic numbering) and months (Roman numbering) are specified. 
(Rheocricotopus) effusus (Walker, 1856); Tavastia yggdrasilia Brodin, Lundström and Paasivirta, 2008.

Fly from spring to autumn: Bryophaenocladius vernalis (Goetghebuer, 1921); Camptocladius stercorarius (De Geer, 1776); Corynoneura lobata Edwards, 1924; Cricotopus (s. str.) cf. algarum (Kieffer, 1911); C. (s. str.) tibialis (Meigen, 1804); C. (Isocladius) cf. sylvestris (Fabricius, 1794); Eukiefferiella gracei (Edwards, 1929); Limnophyes natalensis (Kieffer, 1914); Limnophyes pumilio (Holmgren, 1869); Metriocnemus (s. str.) fuscipes (Meigen 1818); Pseudosmittia trilobata (Edwards, 1929); Smittia aterrima (Meigen, 1818); S. extrema (Holmgren, 1869); S. leucopogon (Meigen, 1804); Thienemanniella obscura Brundin, 1947.

Fly only in spring: Chaetocladius (s. str.) piger (Goetghebuer, 1913); Ch. (s. str.) suecicus (Kieffer, 1916); Cricotopus (s. str.) flavocinctus (Kieffer, 1924); Diamesa parancysta SerraTosio, 1983; Hydrobaenus cf. maladistinctus Makarchenko et Makarchenko, 2009; H. vernus Krasheninnikov et Makarchenko, 2011; Metriocnemus (s. str.) albolineatus (Meigen, 1818); M. (s. str.) tristellus Edwards, 1929; Paraphaenocladius pseudirritus Strenzke, 1950; Pseudodiamesa branickii (Nowicki, 1873); Pseudosmittia albipennis (Goetghebuer, 1921); Rheocricotopus (Rheocricotopus) fuscipes (Kieffer, 1909); Trissocladius heterocerus Kieffer, 1908.

Fly from summer to autumn: Corynoneura coronata Edwards, 1924; C. edwardsi Brundin, 1949; Cricotopus (s. str.) trifascia Edwards, 1929; Limnophyes pentaplastus (Kieffer, 1921); Nanocladius (s. str.) rectinervis (Kieffer, 1911); Paraphaenocladius impensus (Walker, 1856).

Fly in spring and in autumn: Sympotthastia cf. macrocera Serra-Tosio, 1973; Diplocladius cultriger Kieffer, 1908; Eukiefferiella minor (Edwards, 1929); Orthocladius (s. str.) wetterensis Brundin, 1956.

Fly only in autumn: Brillia bifida (Kieffer, 1909); Eukiefferiella brevicalcar (Kieffer, 1911); Paracladius quadrinodosus Hirvenoja, 1973.

Fly from autumn to spring including winter: Diamesa tonsa (Haliday, 1856).

The flight period of chironomids in the Middle Urals was observed throughout the year. Six peaks of activity were observed during the year: early-spring, late-spring, July, latesummer, early-autumn and winter peaks (Figure 1). The maximum period of activity by chironomids and the greatest diversity was recorded in July whereas minimum activity and lowest diversity occurs in winter.

A comparison of chironomid phenology was carried out for two different types of rivers, the Sylva River and the
Irgina River (with a hydrosulphuric spring). Flight periods of chironomids from the Sylva River (on a site between the village of Torgovishche and the town of Suksun) are given in Table 1 and for the hydrosulphuric spring by the Irgina River (near the town of Klyuchi) are given in Table 2. Differences in the flight periods are noted for three species of the 22 common to both these rivers. On the Sylva River site Diamesa tonsa (Haliday) does not fly in autumn but instead flies in the winter there. Orthocladius (s. str.) wetterensis Brundin and Sympotthastia cf. macrocera Serra-Tosio fly in the spring on the Sylva River but on the Irgina River site they fly in the autumn.

\section{DISCUSSION}

Maximum adult species diversity in the subfamilies Diamesinae, Prodiamesinae and Orthocladiinae of the Middle Urals occurs in the summer, in contrast to southern Swedish lakes where it occurs in the spring (Brundin 1949). The same pattern found in the Middle Urals is typical for subarctic Swedish lakes (Brundin 1949) and the Lower Amur River basin (Yavorskaya 2010).

A comparison of the flight periods was carried out for chironomids of the Middle Urals and southern Swedish lakes. Acricotopus lucens (Zetterstedt), Corynoneura carriana Edwards and Cricotopus (s. str.) tibialis (Meigen) have a longer flight period in the Middle Urals but for Corynoneura lacustris Edwards, Cricotopus (s. str.) albiforceps (Kieffer), C. (s. str.) bicinctus (Meigen), $C$. (s. str.) festivellus (Kieffer) and $C$. (s. str.) triannulatus (Macquart) the flight period is shorter. Flight periods of Corynoneura scutellata Winnertz and Cricotopus (Isocladius) sylvestris (Fabricius) in the Middle Urals and southern Sweden are similar. Corynoneura edwardsi Brundin in the Middle Ural flies from summer to autumn but not in spring as in southern Sweden. In the Middle Urals Potthastia longimanus Kieffer flies in summer but not in spring whereas Diplocladius cultriger Kieffer flies in both the spring and in the autumn.

The collecting method used in this study was sweepnetting, and there is a fairly high possibility that certain species were not recorded at times where they actually were flying. The presence of fragmented and short flight periods for some of the species in tables 1 and 2 indicate that this is true (e.g. Metriocnemus (s. str.) fuscipes (Meigen) and Smittia aterrima (Meigen) in Table 1) and the flight periods for these species probably are continuous and/or longer. Also, since adult females were not identified, the phenology of the species reported here is based on the recorded males. For less abundant species or species with a female biased sex-ratio, the true flight periods for the species probably are longer. These potential errors may make comparison in phenology of species between sites inaccurate. However, in the case of the species that displayed different phenologies at the Sylva and Irgina Rivers (Diamesa tonsa (Haliday), Orthocladius (s. str.) wetterensis Brundin 
Table I. Periods of sampled adult chironomids on the Sylva River (between the village of Torgovishche and the town of Suksun).

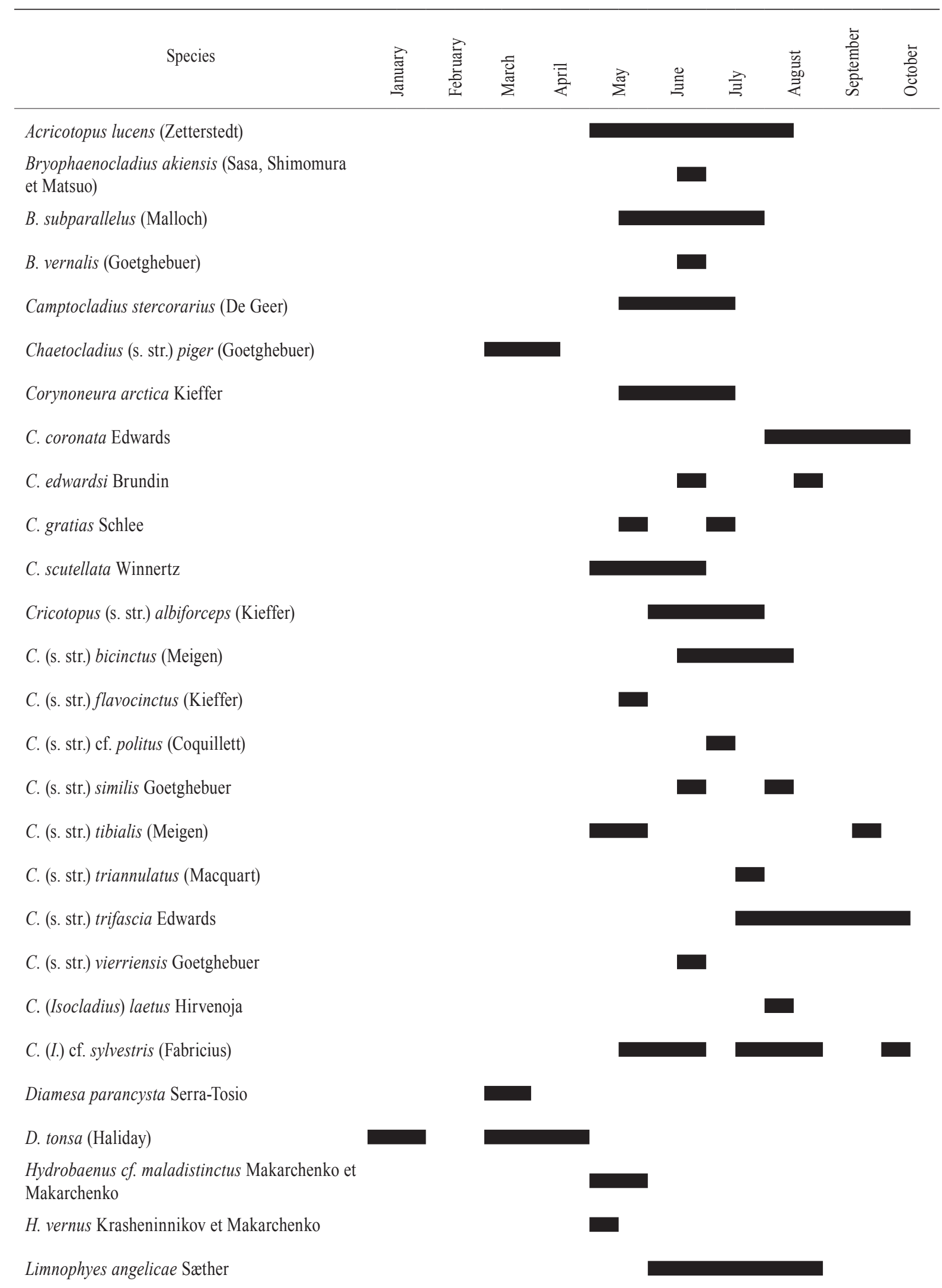


Table I. Continued.

Species

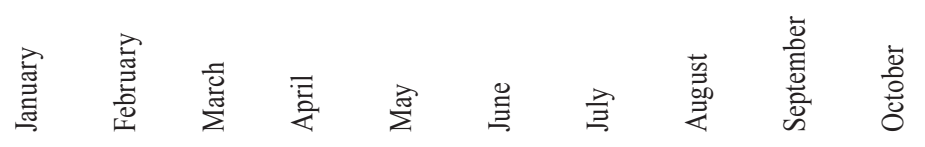

L. asquamatus Søgaard Andersen

L. edwardsi Sæther

L. minimus (Meigen)

L. natalensis (Kieffer)

L. pumilio (Holmgren)

Metriocnemus (s. str.) albolineatus (Meigen)

M. (s. str.) fuscipes (Meigen)

M. (s. str.) picipes (Meigen)

M. (s. str.) tristellus Edwards

Nanocladius (s.str.) distinctus (Malloch)

$N$. (s.str.) cf. minimus Sæther

$N$. (s.str.) rectinervis (Kieffer)

Orthocladius (s. str.) wetterensis Brundin

Parakiefferiella smolandica (Brundin)

Paraphaenocladius impensus (Walker)

Paratrichocladius rufiventris (Meigen)

Pseudodiamesa branickii (Nowicki)

Pseudosmittia danconai (Marcuzzi)

P. mathildae Albu

P. trilobata (Edwards)

Rheocricotopus (Psilocricotopus) chalybeatus (Edwards)

Smittia aterrima (Meigen)

S. extrema (Holmgren)

S. leucopogon (Meigen)

Sympotthastia cf. macrocera Serra-Tosio

Thienemanniella oyabedilata Sasa, Kawai et Ueno 
Table 2. Periods of sampled adult chironomids in the outflow of the hydrosulphuric spring by the Irgina River (near the town of Klyuchi).

Species $\quad$ 总

Acricotopus lucens (Zetterstedt)

Allocladius nanseni (Kieffer)

Brillia bifida (Kieffer)

Bryophaenocladius akiensis (Sasa,

Shimomura et Matsuo)

Chaetocladius (s. str.) piger (Goetghebuer)

Corynoneura arctica Kieffer

C. lobata Edwards

Cricotopus (s. str.) cf. algarum (Kieffer)

C. (s. str.) similis Goetghebuer

C. (s. str.) trifascia Edwards

C. (s. str.) vierriensis Goetghebuer

C. (I.) cf. sylvestris (Fabricius)

Diamesa tonsa (Haliday)

Diplocladius cultriger Kieffer

Doncricotopus dentatus Tuiskunen

Eukiefferiella gracei (Edwards)

Limnophyes natalensis (Kieffer)

L. pentaplastus (Kieffer)

Metriocnemus (s. str.) albolineatus (Meigen)

M. (s. str.) eurynotus (Holmgren)

M. (s. str.) fuscipes (Meigen)

Nanocladius (s. str.) balticus (Palmén)

$N$. (s. str.) rectinervis (Kieffer)

Orthocladius (s. str.) wetterensis Brundin

Paracladius conversus (Walker)

Paraphaenocladius pseudirritus Strenzke

Paratrichocladius goetghebueri Spies 


\begin{tabular}{|c|c|c|c|c|c|c|c|c|c|c|}
\hline Species & $\begin{array}{l}\text { 䓌 } \\
\text { 壳 }\end{array}$ & 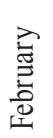 & 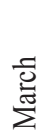 & 砉 & $\sum_{\Sigma}^{\mathrm{E}}$ & 导 & $\vec{\Xi}$ & 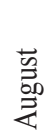 & 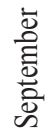 & $\begin{array}{l}\dot{\bar{d}} \\
0 \\
0 \\
0 \\
0\end{array}$ \\
\hline \multicolumn{11}{|l|}{ P. rufiventris (Meigen) } \\
\hline \multicolumn{11}{|l|}{ Potthastia longimanus Kieffer } \\
\hline \multicolumn{11}{|l|}{ Prodiamesa olivacea (Meigen) } \\
\hline \multicolumn{11}{|l|}{ Pseudodiamesa nivosa (Goetghebuer) } \\
\hline \multicolumn{11}{|l|}{ Pseudosmittia danconai (Marcuzzi) } \\
\hline \multicolumn{11}{|l|}{ P. trilobata (Edwards) } \\
\hline \multicolumn{11}{|l|}{$\begin{array}{l}\text { Rheocricotopus (Psilocricotopus) atripes } \\
\text { (Kieffer) }\end{array}$} \\
\hline \multicolumn{11}{|l|}{ Rh. (s. str.) effusus (Walker) } \\
\hline \multicolumn{11}{|l|}{ Smittia aterrima (Meigen) } \\
\hline \multicolumn{11}{|l|}{ S. extrema (Holmgren) } \\
\hline \multicolumn{11}{|l|}{ S. leucopogon (Meigen) } \\
\hline \multicolumn{11}{|l|}{ Sympotthastia cf. macrocera Serra-Tosio } \\
\hline \multicolumn{11}{|l|}{ Thienemanniella obscura Brundin } \\
\hline Th. oyabedilata Sasa, Kawai et Ueno & & & & & & & & & & \\
\hline
\end{tabular}

and Sympotthastia cf. macrocera Serra-Tosio) this likely is unimportant since the observed differences in flight periods are so distinct.

\section{ACKNOWLEDGMENTS}

I am very grateful to E.A. and M.A. Makarchenko for help with the determination of some chironomid species and for their support in these investigations.

\section{REFERENCES}

Aleksevnina MS. 1988. Fam. Chironomidae. In: Biology of Votkinsky Reservoir Irkutsk. pp. 167-168 (in Russian).

Brundin L. 1947. Zur Kenntnis der schwedischen Chironomiden. Ark. Zool. 39 (3): 1-95.

Brundin L. 1949. Chironomiden und andere Bodentiere der südschwedischen Urgebirgsseen. Reports from the Institute of Freshwater Research, Drottningholm 30, 914 p.

Brundin L. 1956. Zur Systematik der Orthocladiinae (Diptera, Chironomidae). Rep. Inst. Freshwat. Res. Drottningholm. 37:
1-185.

Brundin L. 1966. Transantarctic relationships and their significance, evidenced by chironomid midges. With a monograph of the subfamilies Podonominae and Aphroteniinae and the austral Heptagyiae. Kungliga svenska vetenskapsakademiens handlingar 4 (11), $472 \mathrm{pp}$.

Cranston PS, Sæther OA. 1982. A redefinition of Acamptocladius Brundin, 1956 (syn. Phycoidella Sæther, 1971, syn. nov.) (Diptera, Chironomidae), with the description of $A$. reissi sp. n. Entomologica scandinavica 13: 25-32.

Cranston PS, Oliver DR, Sæther OA. 1989. The adult males of Orthocladiinae (Diptera: Chironomidae) of the Holarctic region - Keys and diagnoses. Entomologica scandinavica Supplement 34: $165-352$.

Fu Y, Sæther OA, Wang X. 2009. Corynoneura Winnertz from East Asia, with a systematic review of the genus (Diptera: Chironomidae: Orthocladiinae). Zootaxa 2287: 1-44.

Fu Y, Sæther OA, Wang X. 2010a. Thienemanniella Kieffer from East Asia, with a systematic review of the genus (Diptera: Chironomidae: Orthocladiinae). Zootaxa 2431: 1-42.

Fu Y, Wang X, Andersen T. 2010b. Chinese Paracladius Hirvenoja, with the description of $P$. ovatus sp. n. (Chironomidae: Orthocladiinae). Zootaxa 2453: 62-68.

Gromov VV. 1951. List of some Tendipedidae of the Kama River 
with identification of all stages. Proceed. ENI of Perm State University 13(2-3): 119-135 (in Russian).

Gromov VV. 1953. Bottom fauna, its yearly dynamics in the Kama River and changes due to pollution. Dissertation of Biological science Candidate. Perm. 286 p (in Russian).

Hirvenoja M. 1973. Revision der Gattung Cricotopus van der Wulp und ihrer Verwandten (Diptera, Chironomidae). Annales Zoologici Fennici. 10: 1-363.

Hirvenoja M, Hirvenoja E. 1988. Corynoneura brundini spec. nov. Ein Beitrag zur Systematik der Gattung Corynoneura (Diptera, Chironomidae). Spixiana 14: 213-238.

Langton PH, Pinder LCV. 2007. Keys to the adult male Chironomidae of Britain and Ireland. Freshwater Biological Association Scientific Publications 64. Vol. 1, 227 p. Vol. 2, $168 \mathrm{p}$.

Lehmann J. 1969. Die europäischen Arten der Gattung Rheocricotopus Thien. and Harn. und drei neue Artenvertreter dieser Gattung aus der Orientalis (Diptera, Chironomidae). Archiv für Hydrobiologie. 66: 348-381.

Lehmann J. 1972. Revision der europäischen Arten (Puppen und Imagines) der Gattung Eukiefferiella Thienemann. Beiträge zur Entomologie 22: 347-405.

Makarchenko EA. 1985. Chironomids of the Soviet Far East Subfamilies Podonominae, Diamesinae and Prodiamesinae. Vladivostok, DVNC AN SSSR. 208 p (in Russian).

Makarchenko EA. 1998. Chironomids of the subfamily Diamesinae (Diptera, Chironomidae) of the Northern Hemisphere (systematics, biology, biogeography). Dissertation of Biological science Doctor. Vladivostok. 493 p (in Russian).

Makarchenko EA. 2006. Subfam. Prodiamesinae. In: Opredelitel' Nasekomykh Dal'nego Vostoka Rossii. Dal'nauka, Vladivostok. Suppl. 6(4): 276-280, 480-482, 622-623 (in Russian).

Makarchenko EA, Makarchenko MA. 2005. New species of chironomids (Diptera, Chironomidae) of the Russian Far East. In: Vladimir Ya. Levanidov's Biennial Memorial Meetings. Dal'nauka, Vladivostok. Suppl. 3: 374-382. (in Russian).

Makarchenko EA, Makarchenko MA. 2006a. Subfam. Orthocladiinae. In: Opredelitel' Nasekomykh Dal'nego Vostoka Rossii. Dal'nauka, Vladivostok. Suppl. 6(4): 280-372, 482-530, 623-671 (in Russian).

Makarchenko EA, Makarchenko MA. 2006b. Chironomids of the genera Corynoneura Winnertz, 1846 and Thienemanniella Kieffer, 1919 (Diptera, Chironomidae, Orthocladiinae) of the Russian Far East. Euroasian Entomological Journal. Suppl. 5(2): 151-162 (in Russian).

Makarchenko EA, Makarchenko MA. 2009a. New records of chironomids (Diptera, Chironomidae, Orthocladiinae) in Far East and bodering territories. VII. Bryophaenocladius Thienemann. Euroasian Entomological Journal. Suppl. 8(1): 51-63 (in Russian).

Makarchenko EA, Makarchenko MA. 2009b. New records of chironomids (Diptera, Chironomidae, Orthocladiinae) in Far East and bordering territories. VI. Hydrobaenus Fries. Euroasian Entomological Journal. Suppl. 8(1) 33-50 (in Russian).

Makarchenko EA, Makarchenko MA. 2010a. A review of Parakiefferiella Thienemann (Diptera, Chironomidae, Orthocladiinae) from the Russian Far East. Euroasian Entomological Journal 9(3): 397-410 (in Russian).

Makarchenko EA, Makarchenko MA. 2010b. New data on the fauna and taxonomy of Corynoneura Winnertz (Diptera, Chironomidae, Orthocladiinae) for the Russian Far East and bordering territories. Euroasian Entomological Journal. Suppl. 9(3): 353-370 (in Russian).

Makarchenko EA, Makarchenko MA. 2010c. New findings of chironomids (Diptera, Chironomidae, Orthocladiinae) from the Far East and bordering territories.IX. Genus Eukiefferiella Thienemann. Euroasian Entomological Journal. Suppl. 9(1): 65-82 (in Russian).

Oliver DR, Roussel ME. 1983. Redescription of Brillia Kieffer (Diptera: Chi-ronomidae) with descriptions of three Nearctic species. Canadian Entomologist 115: 257-279.

Pankov NN. 2004. Structural and functional characteristics of the Sylva River zoobenthos communities (Kama River basin). Perm. 162 p (in Russian).

Pozdeev IV. 2010. Chironomid fauna (Diptera, Chironomidae) of the Kama River basin. Biology of Inland Waters 4: 5-14 (in Russian).

Rossaro B, Lencioni V. 2000. Revision of the genus Smittia Holmgren, 1869 (Diptera, Chironomidae, Orthocladiinae). Bollettino di Zoologia Agraria e di Bachicoltura 32(2): 97-105.

Sæther OA. 1969. Some Nearctic Podonominae, Diamesinae and Orthocladiinae (Diptera: Chironomidae). Bulletin of the Fisheries Research Board of Canada 170: 1-154.

Sæther OA. 1975. Twelve new species of Limnophyes Eaton, with keys to Nearctic males of the genus (Diptera: Chironomidae). Canadian Entomologist 107: 1029-1056.

Sæther OA. 1976. Revision of Hydrobaenus Fries, Trissocladius Kieffer, Zalutschia Lipina, Paratrissocladius Zavrel and some related genera (Diptera: Chironomidae). Bulletin of the Fisheries Research Board of Canada 195: 1-287.

Sæther OA. 1977. Taxonomic studies on Chironomidae: Nanocladius, Pseudochironomus, and the Harnischia complex. Bulletin of the Fisheries Research Board of Canada 196: 1-143.

Sæther OA. 1985a. A review of Odontomesa Pagast, 1947 (Diptera, Chironomidae, Prodiamesinae). Spixiana Suppl. 11: 15-29.

Sæther OA. 1985b. A review of the genus Rheocricotopus Thienemann and Harnisch, 1932, with the description of three new species (Diptera, Chironomidae). Spixiana 11: 59-108.

Sæther OA. 1989. Metriocnemus van der Wulp: a new species and a revision of species described by Meigen, Zetterstedt, Stæger, Holmgren, Lundström and Strenzke. (Diptera: Chironomidae). Entomologica scandinavica 19: 393-430.

Sæther OA. 1990. A review of the genus Limnophyes Eaton from the Holarctic and Afrotropical region (Diptera: Chironomidae, Orthocladiinae). Entomologica scandinavica 35: 1-139.

Sæther OA. 1995. Metriocnemus van der Wulp: Seven new species, revision of type material and new records (Diptera: Chironomidae). Annales de limnologie 31: 35-64.

Sæther OA. 2004. The chironomids (Diptera, Chironomidae) described by Lundström (1915) from arctic Siberia, with a redescription of Derotanypus sibiricus (Kruglova and Chernovskii). Zootaxa 595: 1-35.

Sæther OA, Wang X. 1995. Revision of the genus Paraphaenocladius Thienemann, 1924 of the world (Diptera, Chironomidae, Orthocladiinae). Entomologica scandinavica 48: 3-69.

Sæther OA, Sublette JE, Willassen E. 1984. Chironomidae(Diptera) from the 2nd Fram Expedition (1898-1902) to Arctic North America described by J. J. Kieffer. Entomologica scandinavica 
15: 249-275.

Schlee D. 1968. Vergleichende Merkmalsanalyse zur Morphologie und Phylogenie der Corynoneura - Gruppe (Diptera, Chironomidae). Zugleich eine allgemeine Morphologie der Chironomiden-Imago. Stuttgarter Beiträge zur Naturkunde 180: $1-150$.

Shilova AJ. 1976. Chironomids of the Rybinsk Reservoir. Nauka, Leningrad, $251 \mathrm{p}$ (in Russian).

Strenzke K. 1950. Systematik, Morphologie und Ökologie der terrestrischen Chironomiden. Archiv für Hydrobiologie, Suppl. 18: 207-414.

Strenzke K. 1960. Terrestrische Chironomiden XIX-XXIII (Diptera, Chironomidae). Deutsche Entomologische Zeitschrift 7: 414-441.

Tauson AO. 1947. Water resource of the Molotov Region. Molotov. $321 \mathrm{p}$ (in Russian).

Tuiskunen J. 1985. A description of Psilometriocnemus europaeus sp. n. and Doncricotopus dentatus sp. n. (Diptera, Chironomidae, Orthocladiinae) from Finland. Annales Entomologici Fennici 51: 101-104.

Tuiskunen J. 1986. The Fennoscandian species of Parakiefferiella Thienemann (Diptera, Chironomidae, Orthocladiinae). Annales Zoologici Fennici 23: 175-196.

Tuiskunen J, Lindeberg B. 1986. Chironomidae (Diptera) from Fennoscandia north of $68^{\circ} \mathrm{N}$, with a description of ten new species and two new genera. Annales Zoologici Fennici 23: 361-393.

Willassen E, Hanssen O, Koksvik JI. 2005. Diamesa parancysta Serra-Tosio: an East-Palearctic midge new to Europe (Diptera: Chironomidae: Diamesinae). Norwegian Journal of Entomolgy 52: 69-73.

Yavorskaya NM. 2010. Chironomids (Diptera, Chironomidae) of the Lower Amur River basin. Dissertation of Biological science Candidate. Vladivostok. 266 p (in Russian). 